\title{
Estimation of Natural Variability and Detection of Anthropogenic Signal in Summertime Precipitation over South America
}

\author{
Stefanie Talento ${ }^{1,2}$ and Marcelo Barreiro ${ }^{1}$ \\ ${ }^{1}$ Unidad de Ciencias de la Atmósfera, Facultad de Ciencias, Universidad de la República, Iguá 4225, \\ Montevideo 11400, Uruguay \\ ${ }^{2}$ Instituto de Matemática y Estadistica Rafael Laguardia, Facultad de Ingeniería, Universidad de la República, \\ Herrera y Reissig 565, Montevideo 11300, Uruguay \\ Correspondence should be addressed to Stefanie Talento, stalento@fisica.edu.uy
}

Received 27 March 2012; Revised 8 July 2012; Accepted 12 July 2012

Academic Editor: Soon-Il An

Copyright (C) 2012 S. Talento and M. Barreiro. This is an open access article distributed under the Creative Commons Attribution License, which permits unrestricted use, distribution, and reproduction in any medium, provided the original work is properly cited.

\begin{abstract}
We use a coupled model to estimate the natural variability of summertime rainfall over South America and to determine the time horizon when anthropogenic forcing will start having an effect on it. We use a combination of three experiments: preindustrial, 20th century, and the projected changes under A1B scenario. The first empirical orthogonal function of rainfall in DecemberFebruary is used to characterize summertime variability. The model can display two different regimes of natural variability of this mode. In one regime, there is a strong coupling between the South Atlantic convergence zone (SACZ) and the Atlantic Ocean. In the other regime, the SACZ is dominated by internal atmospheric variability. The detection of the impact of anthropogenic forcing is calculated comparing the probability density functions (pdfs) of the preindustrial run with the one under the A1B scenario. We found that the detection strongly depends on the pdf used to characterize internal climate variability. If the pdf of the mode with coupling between the SACZ and the Atlantic Ocean is used, the anthropogenic influence is felt very early within the future scenario (in less than 30 years). On the contrary, with the pdf that characterizes an SACZ dominated by internal atmospheric variability, the forcing is detected only several (almost 50) years into the scenario.
\end{abstract}

\section{Introduction}

Understanding and quantifying the amplitude of the natural variability, internal to the climate system, is crucial to predict the behavior of the system in the next decades, when the response to externally imposed forcing (such as anthropogenic greenhouse gases) is expected to be weaker than or comparable to the natural climate variations (e.g., $[1,2])$.

There are three general approaches to estimate natural variability: analysis of instrumental records, analysis of paleoclimate proxies, or climate models.

The use of actual observations has a number of shortcomings: short time series, contamination by anthropogenic signals, not available in every region of the planet, and so forth. An attempt to filter the anthropogenic signal is done in Jones and Hegerl [3].
Paleoclimate proxies are also not available in every region of the planet (the lack is particularly acute in the southern hemisphere) and often are not perfect indicators. However, proxies serve as checks on the climate variability simulated by models. For example, Collins et al. [4] compare simulated variability with proxy reconstruction of past variability.

Therefore, and given the above comments, estimates of natural variability are generally model-based $[5,6]$. Global climate models, operated in a control-run mode, may offer the best chance to estimate natural variability provided that they accurately reproduce the natural low frequency variability in the variable and region of interest. For example, Stott et al. [7] and Tett et al. [8] directly use a control run to estimate natural variability, while Swanson et al. [9] propose a technique that identifies the global mean surface temperature fluctuations attributable to long-term natural variability 
analyzing control simulations and assuming that the likely source for such variability is the ocean.

In this work, we focus on summer precipitation over La Plata Basin (LPB). The projected changes in mean summer precipitation in LPB for the end of the 21st century by a multimodel mean, under A1B scenario, show a dipole-like structure with decreased precipitation in LPB and increase to the north of it. This rainfall change pattern has been related to an increase in the occurrence of the negative phase of the leading summertime pattern of interannual variability [10]. This pattern of variability is dipole-like, with opposite centers of action over the South Atlantic convergence zone (SACZ) and Southeastern South America (SESA); it has been widely studied and shown to be recurrent in time scales of variability that range from subseasonal to decadal [11-16]. In addition, models are able to correctly reproduce the space and time features of this mode of variability [10]. Given these results, the aim of this study is to estimate the natural variability of this precipitation pattern and to use this estimation to identify variations in the regional climate that cannot be attributed to natural oscillations in the climate system.

As observations of precipitation over South America are only available during the 20th century, the variability present in their recordings may reflect a mixture between natural and anthropogenically forced variability. As a consequence, and in order to understand the unforced part of the variability, we appeal to model simulations.

We use the output of the HadCM3 coupled model (which is one of the models that shows an increase of the negative phase of the leading mode of precipitation variability as trend in the 21st century) and use a combination of three experiments: a preindustrial run, a 20th-century run and a projection run done under A1B scenario. The 20th-century run is used to validate the model, the preindustrial run is used to estimate the natural variability, and the future scenario run is used to detect a possible anthropogenic signal. As will be shown, this detection is highly dependent on the estimation of natural variability.

The paper is organized as follows. In Section 2, we introduce the datasets, the model, and the methodology to be used. In Section 3, we characterize the precipitation climate variability over South America during summertime. In Section 4, we analyze the natural variability, using the preindustrial simulation. In Section 5, we study the detection of anthropogenic forcing under the future scenario $\mathrm{A} 1 \mathrm{~B}$ and determine when the variability can no longer be attributed to natural sources. Finally, in Section 6, we summarize and discuss the results.

\section{Datasets, Model, and Methodology}

2.1. Data and Model. The precipitation data consist of monthly values, from 1979 to 2009 , in a $2.5^{\circ} \times 2.5^{\circ}$ grid obtained from Xie and Arkin [17] and is the result of merging observations from rain gauges with rainfall estimates from several satellites.

The sea surface temperature (SST) data set consists of monthly values, from 1979 to 2009, from NOAA_ERSST_V3 provided by the NOAA/OAR/ESRL PSD, Boulder, Colorado, USA, from their web site at http://www.esrl.noaa.gov/psd/ with a resolution of $2^{\circ} \times 2^{\circ}$.

We use output from the runs of the HadCM 3 coupled model [18]. In particular, we use one preindustrial experiment which is 341 years long, the 20th-century run, and the future scenario A1B that runs up to year 2200. The output of the preindustrial run included a few missing values that were removed before the analysis. The model was selected because it has been shown to represent adequately the climate over South America [10] and because of the availability of a very long preindustrial run. By definition, all the variability encountered in the preindustrial run is natural variability (in addition, the total solar irradiance is held constant and no natural emissions of sulfur aerosols are considered). On the other hand, the 20th century and future scenario runs may also contain forced variability and will be used to detect anthropogenic forcing. In the 20th-century and scenario A1B runs, the radiative forcing agents are anthropogenic greenhouse gases and aerosols; again the total solar irradiance is held constant and no volcanic forcing is included. A more detailed description of the specifications of the model runs can be found in http://www-pcmdi.llnl.gov/ipcc/ model_documentation/HadCM3.htm.

As this study focuses on austral summer, here defined as December-January-February (DJF), we compute the DJF means of every field of interest by taking averages from the monthly means. Anomalies are calculated as the difference between the actual seasonal means and the climatology.

2.2. Methodology. The methodology consists of several steps. First, we define the precise precipitation pattern to study. This pattern is obtained as the first empirical orthogonal function (EOF) of DJF precipitation in southern South America $\left(50^{\circ} \mathrm{S}-10^{\circ} \mathrm{S} ; 280^{\circ} \mathrm{E}-330^{\circ} \mathrm{E}\right)$, in the HadCM3 20thcentury run. We will call this pattern EOF1.

Second, we validate the simulated pattern comparing it against observed analogous. We compare the EOF1 and the associated SST pattern obtained with the HadCM3 20thcentury run against the analogous fields obtained using the observations in the 1979-2009 period.

Third, to quantify the EOF1 variability under no external forcing, we project the HadCM3 preindustrial run precipitation anomalies onto the EOF1 spatial pattern. The anomalies are calculated with respect to the climatology of the 20thcentury experiment.

To determine changes in the pattern under anthropogenic forcing, we project the HadCM3 A1B run precipitation anomalies onto the simulated EOF1 pattern calculated using the 20th-century run. As for the preindustrial case, anomalies are calculated with respect to the 20th-century climatology.

The projection of the experiments onto the EOF1 provides a time series that describes the time evolution of the model for the preindustrial experiment (341 years long) and the A1B scenario (200 years long). This allows the construction of the probability density function (pdf) that characterizes the EOF1 which will be contrasted at different times. 


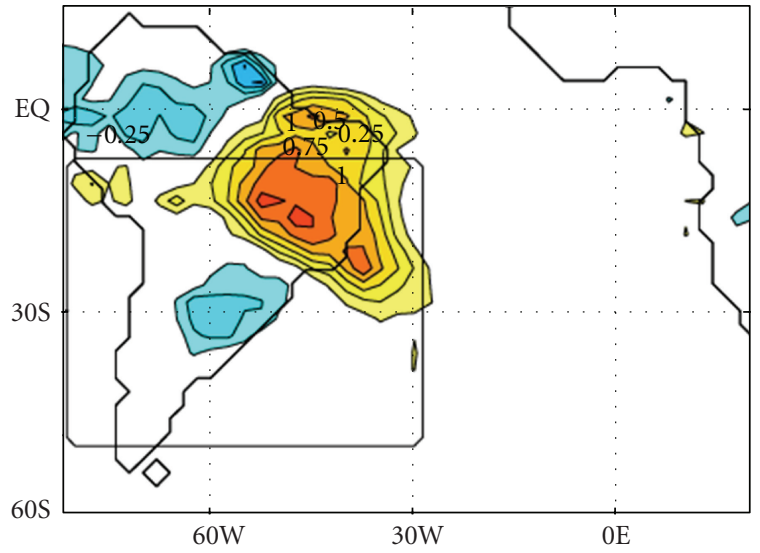

(a)

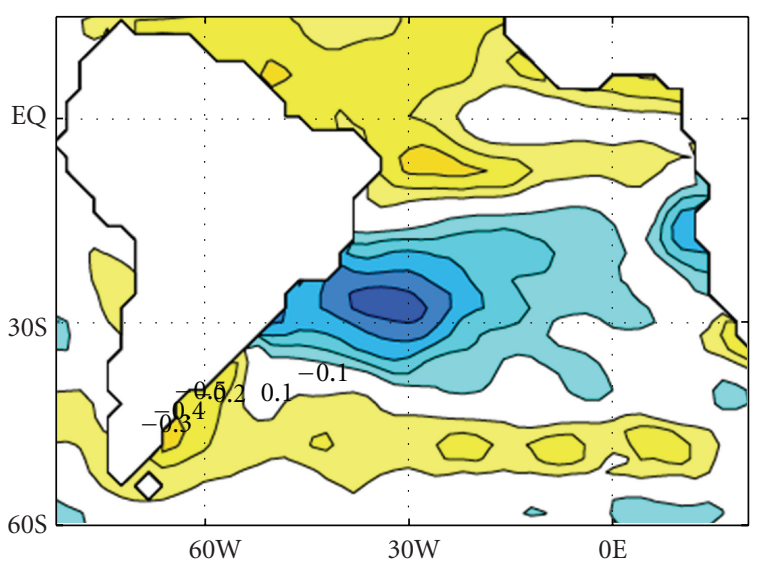

(c)

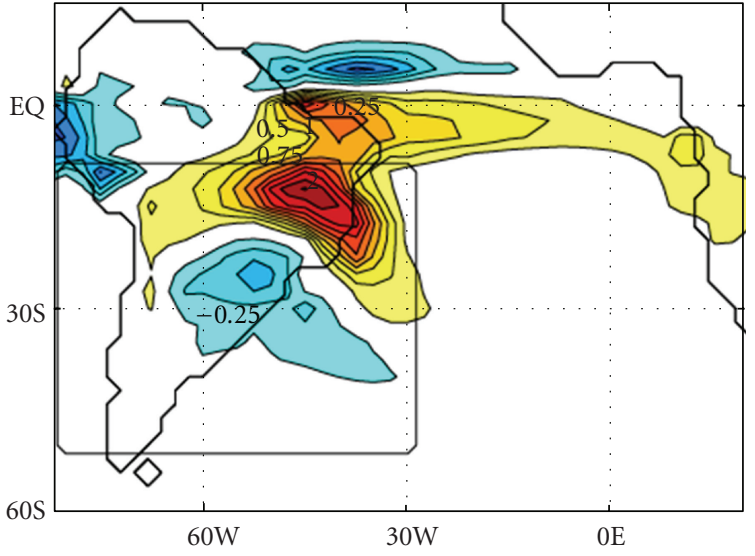

(b)

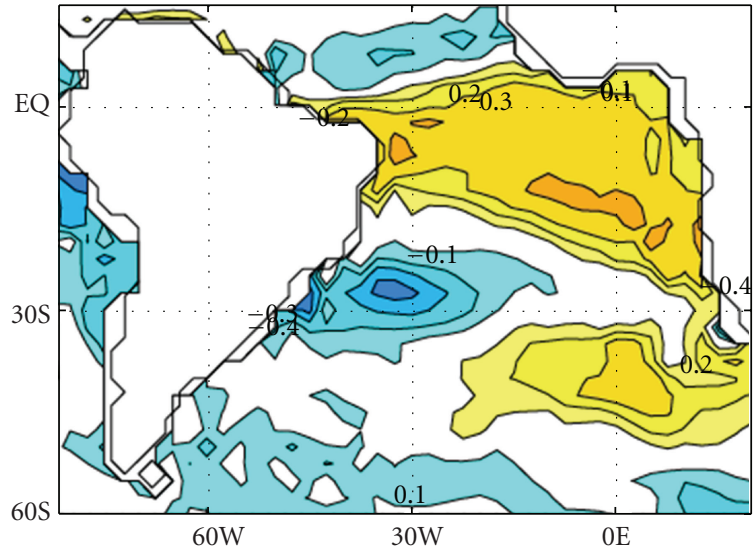

(d)

Figure 1: (a) First EOF of interannual DJF rainfall variability calculated over the region $\left(50^{\circ} \mathrm{S}-10^{\circ} \mathrm{S}\right.$; $\left.280^{\circ} \mathrm{E}-330^{\circ} \mathrm{E}\right)(\mathrm{dashed}$ box $)$ for observations. Contour interval: $0.25 \mathrm{~mm}$ /day. The map is constructed by linear regression of the precipitation field onto the time series associated with the EOF. (b) Idem (a) for the HadCM3 20th-century run. (c) Correlation between time series associated with the EOF shown in (a) and SST anomalies for observations. Contour interval: 0.1. Correlation values higher (lower) than 0.35 ( -0.35$)$ are significant at a 5\% level according to a two-tailed Student $t$-test. (d) Correlation between time series associated with the EOF shown in (b) and SST anomalies for the HadCM3 20th-century run. Contour interval: 0.1. Correlation values higher (lower) than $0.2(-0.2)$ are significant at a $5 \%$ level according to a two-tailed Student $t$-test.

\section{Main Mode of Summertime Rainfall Variability}

We first show that HadCM3 is able to reproduce the main features of summertime precipitation over South America during the 20th century. Figure 1(a) shows the first EOF of observed (Xie-Arkin) rainfall during DJF calculated over the box shown in the figure. The structure consists of a dipole in precipitation with the main center in the SACZ and a weaker center of opposite sign in SESA. The rainfall anomalies in the SACZ are over the continent and the band extends southeastward over the ocean. This EOF explains 35\% of the variance. In addition to the dipole, the regression over a larger region shows a southward shift of the Atlantic Intertropical Convergence Zone (ITCZ) particularly over the continent. The simulated first EOF of rainfall in HadCM3 (EOF1), calculated using the 100 years of the 20th-century run, presents a very similar structure (Figure 1(b)) and explains about the same percentage of total variance (29\%). Anomalies are, however, stronger everywhere. The pattern correlation between observed and simulated EOFs is 0.77 .

In order to test the sensitivity of the EOF1 pattern to the period of the 20th-century run used for its calculation, we performed the same EOF analysis using, instead of the complete 100 years of simulation, sliding windows of 30 years (which is the time length available in the observations). With this procedure we found that the average pattern correlation between the simulated EOF1 and the observed analogous is 0.73 and, in particular, the pattern correlation when the EOF1 is calculated using the last 30 years of simulation (most similar period to the observations) is 0.76 . Hence, the EOF1 pattern obtained using the 100 years of 20th-century simulation can be considered robust and representative of the observed variability.

The correlation of the observed EOF pattern with concurrent seasonal SST shows that it is associated with cold 
SST anomalies between $15^{\circ} \mathrm{S}$ and $35^{\circ} \mathrm{S}$ to the west of $20^{\circ} \mathrm{W}$ (Figure 1(c)). This result is in agreement with Robertson and Mechoso [14] and Chaves and Nobre [19] who show that an enhanced SACZ leads to a cooling due to increased cloudiness. This cooling can then feed back into the oceanic part of the SACZ weakening convection $[20,21]$. In addition to this cooling, there is a hint of positive correlation with SST anomalies to the north of $10^{\circ} \mathrm{S}$, which suggests that the ocean over that region may force rainfall anomalies over the SACZ. This positive correlation is consistent with the southward shift of the ITCZ. As shown in Figure 1(d), the model is able to reproduce these correlations: the negative values off South America between $15-35^{\circ} \mathrm{S}$ and the positive correlation north of $10^{\circ} \mathrm{S}$. The main difference with the observed pattern is the fact that the positive correlations over the tropical Atlantic are stronger and extend from east to west of the basin, while in observations, the positive correlations are limited to the western side of the basin.

\section{Natural Variability: Preindustrial}

4.1. Variability of EOF1 in Preindustrial Run. As mentioned in the introduction, one main objective of this work is to study the variability of the EOF1 pattern under no external forcing. That is, we are interested in determining the longterm variability that may arise due only to ocean-atmosphere interactions internal to the climate system. This will give us an estimate of the possible changes in the dynamics of this pattern and provide an estimate of uncertainty that will serve as the basis for future climate changes.

To address this issue, we consider the preindustrial experiment that is 341 years long and has no external/anthropogenic forcing. In order to study the changes in the variability of the EOF1 of rainfall in the 20th century, we use the time series calculated by projecting the preindustrial rainfall anomalies onto the EOF1.

One way to study the changes in the evolution of the time series of EOF1 is to consider the pdf and how its shape changes with time. We follow the approach of Livina et al. [22] and Kwasniok and Lohmann [23] who treat the climate system as a nonlinear dynamical system which can have multiple states and shifts among these possible states by stochastic forcing. Under this hypothesis, one can construct a one-dimensional conceptual model that is represented by the Langevin equation with a certain potential function $U$ and noise level $\sigma$ :

$$
d z=-U^{\prime}(z) d t+\sigma d W
$$

where $z$ is the climatic variable considered (in this paper: values of EOF1) and $W$ is a standard Wiener process.

Under stationary conditions, there is a one-to-one correspondence between the potential $U$ and the pdf and thus the potential can be calculated given the time series:

$$
U=\frac{-\sigma^{2}}{2} \log p_{d},
$$

where $p_{d}$ is the pdf of the time series.

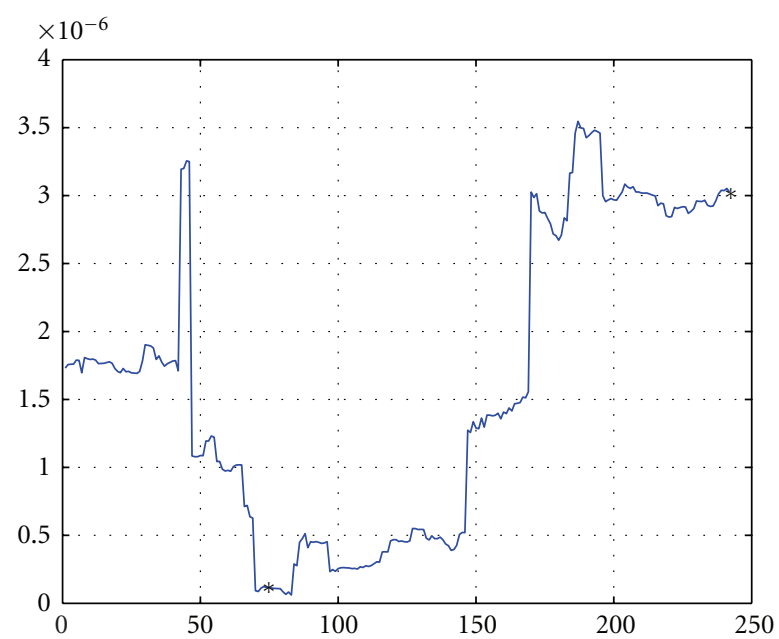

FIGURE 2: Coefficient of 4th-order of the potential associated with the pdf computed using 100-years sliding windows. The larger the value the broader the pdf. The "*” mark is the periods P1 and P2 used in the study, which have different pdfs reflecting different modes of behavior of internal variability in the south American climate.

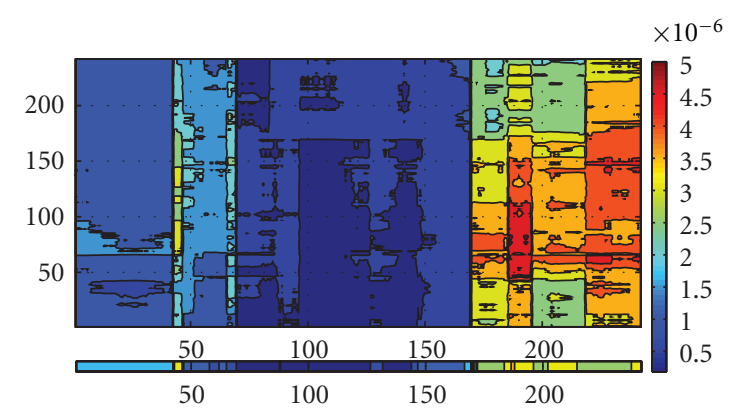

FIGURE 3: Above: coefficient of 4th-order of the potential associated with the pdf using 242 different EOF patterns (first EOF of preindustrial run in sliding periods of 100 years) to project the preindustrial run. Horizontal axis: same as in Figure 2. Vertical axis: starting year of the period for the calculus of the EOF. Below: shows, for comparison, same data plotted in Figure 3 (i.e., using EOF calculated with the 20th-century run: EOF1).

We assume that the potential can be expressed as a 4 thorder polynomial (with no independent term), which is the simplest model that allows for 2 distinct stable states. A leastsquares fit of $-\log p_{d}$ by such a polynomial provides the shape of the potential, independent of $\sigma$ up to a constant factor. The 4th-order coefficient determines the width of the potential: the larger the coefficient the wider the potential and the pdf.

Figure 2 shows the 4 th-order coefficient of the calculated potential considering the estimation of $p_{d} 100$-year sliding windows. As can be seen, there are periods when the coefficient is very small (e.g., for years 75-174, hereafter called $\mathrm{P} 1$ ) and periods when the coefficient is relatively large (years 242-341, hereafter called P2) suggesting different pdfs and, therefore, a different climate behavior. 


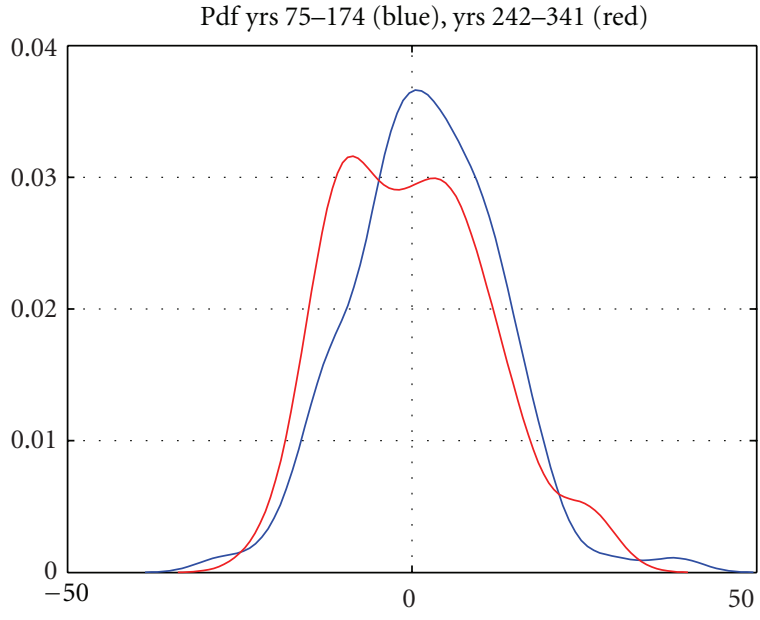

(a)

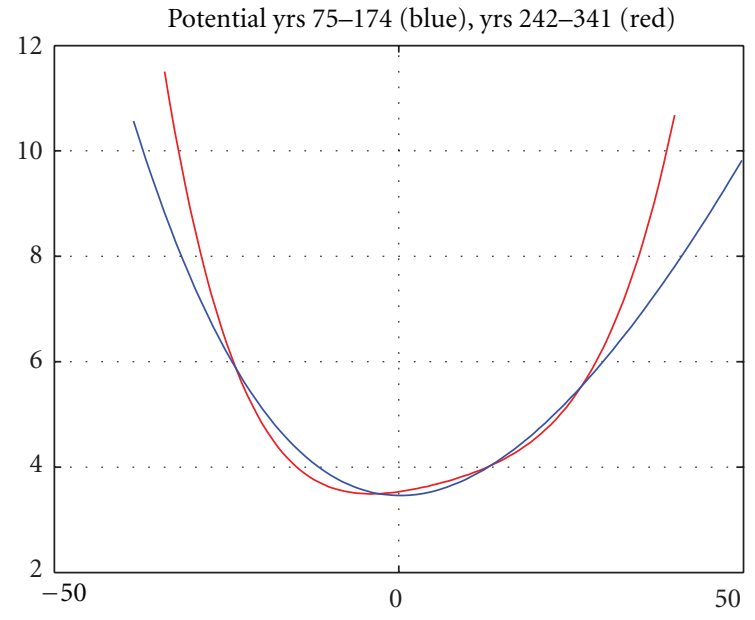

(b)

Figure 4: pdfs (a) and potential (b) of the time series of EOF1 for the preindustrial run during period P1 (years 75-174, blue) and period P2 (years 242-341, red).

4.2. Sensitivity of Results. We have identified P1 and P2 as periods with substantial differences in their pdfs. P1 and P2 were detected using the projection of the preindustrial run onto EOF1, which is a pattern obtained using the 20thcentury run and, thus, might be itself contaminated by external forcing present in this simulation. To show that the identification of P1 and P2 is not seriously compromised by possible contamination of the EOF1 pattern by external forcing, we designed a sensitivity test, described below.

We take sliding windows of 100 years of the preindustrial run and calculate the first EOF of the precipitation, in the same manner we did with EOF1. In this way, we obtain 242 EOF patterns calculated only with the preindustrial run and, hence, not contaminated by external forcing. For each of these patterns, we repeat the procedure explained in the preceding section and obtain the 4 th-order coefficient of the polynomial representing the potential. In Figure 3, we plot the results. According to the figure, independently from the pattern used for the projection two different periods can be identified: one where the 4th-order coefficient is very low (between years 70 and 170) and another where the coefficient is very high (after year 170); these periods include P1 and P2, respectively. In addition, the dispersion of the values of the coefficient is much smaller than the difference between the highest and lowest values, indicating that $\mathrm{P} 1$ and $\mathrm{P} 2$ are clearly different and that the difference between them is significant.

In summary, although EOF1 might be contaminated by external forcing, the identification of $\mathrm{P} 1$ and $\mathrm{P} 2$ as periods with different pdfs is robust and is still maintained when the reference EOF is calculated using the preindustrial (not anthropogenically contaminated) run only.

4.3. Analysis of Variability in P1 and P2. Figure 4 shows the potential for P1 and P2 as well as the associated pdfs. The shape of the pdf is very different in the two cases, having only one maximum in period $\mathrm{P} 1$ and showing 2 maxima in $\mathrm{P} 2$. These two pdfs are statistically different at $10 \%$ according to a Kolmogorov test. We used the kstest 2 routine from MATLAB. Moreover, we tested the bimodality considering each pdf as a mixture of two Gaussian pdfs [24]: the pdf is bimodal if the distance between peaks is larger than the variance of the two associated Gaussians. According to this test, the pdf in period P1 is unimodal while in the latter P2 period, the pdf is bimodal. While an unimodal pdf indicates that the system possesses only one preferred state (which is the state with the highest probability of occurrence), a bimodal pdf indicates that the system possesses two such high-probability states (see discussion).

Figure 5 shows the associated EOF1 patterns and the correlation between the time series and SST anomalies in the two periods considered. In P1, there is a strong correlation with Atlantic SST with the same sign and structure shown in Figure 1, but with values that are higher than in that case. This could be partly due to the length of the time series, but as seen for the period P2 this is not the whole story. In period $\mathrm{P} 2$, the correlations with SST are weaker in both the positive and negative regions. Accompanying these changes in correlation, there are clear differences in the spatial structure of the EOF1. In period P1, when correlations with SST are large, the SACZ has its maximum over the ocean next to the coast, while in the second period of lesser correlation with SST, the SACZ maximum is well into the continent. Over SESA, there are no significant changes in rainfall anomalies. Thus, in the case of strong correlation with SST, the rainfall associated with the SACZ has its maximum over the ocean and the pdf is clearly unimodal. In the case of weak correlation with SST, the SACZ has its maximum inland and the pdf of EOF1 is broad and has two peaks.

A wavelet analysis of the time series of EOF1 provides further clues about the difference between the periods (Figure 6(a)). It reveals that during P1, there is a 50 -year 


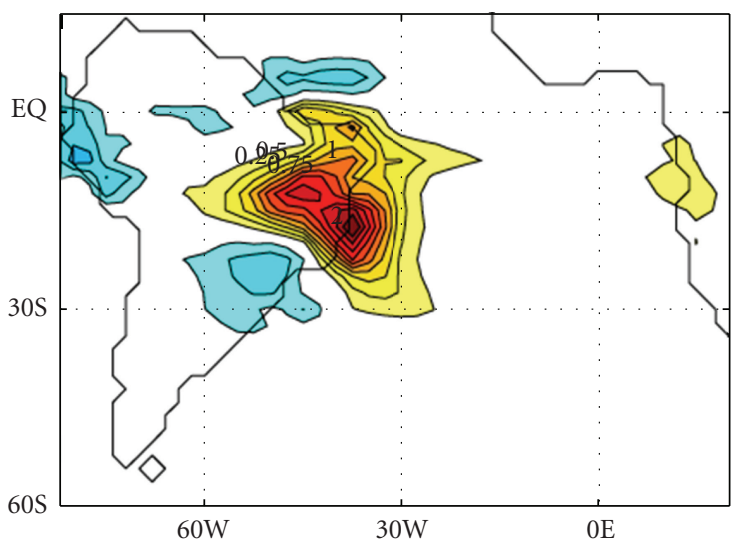

(a)

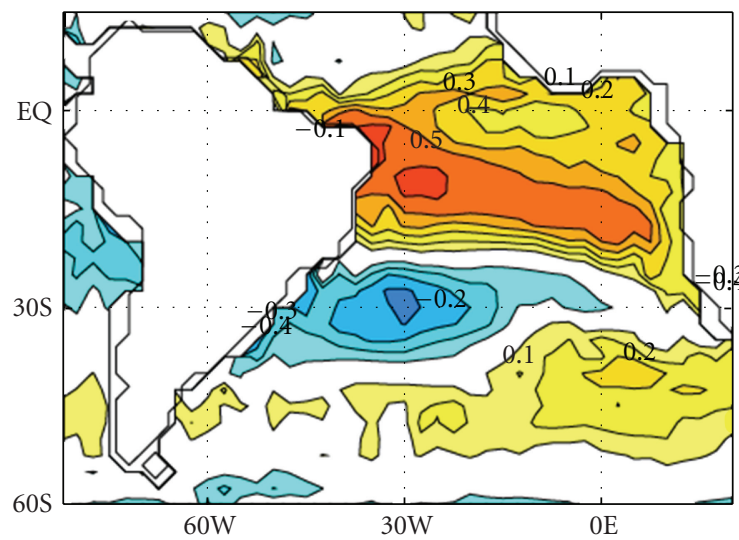

(c)

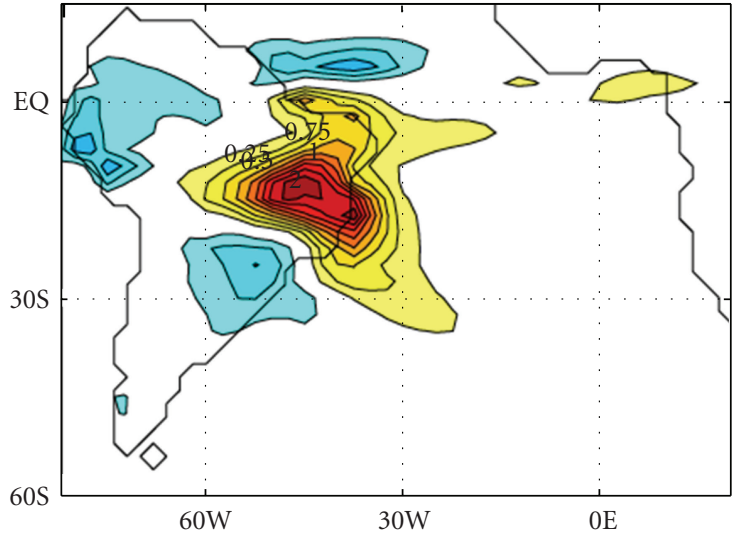

(b)

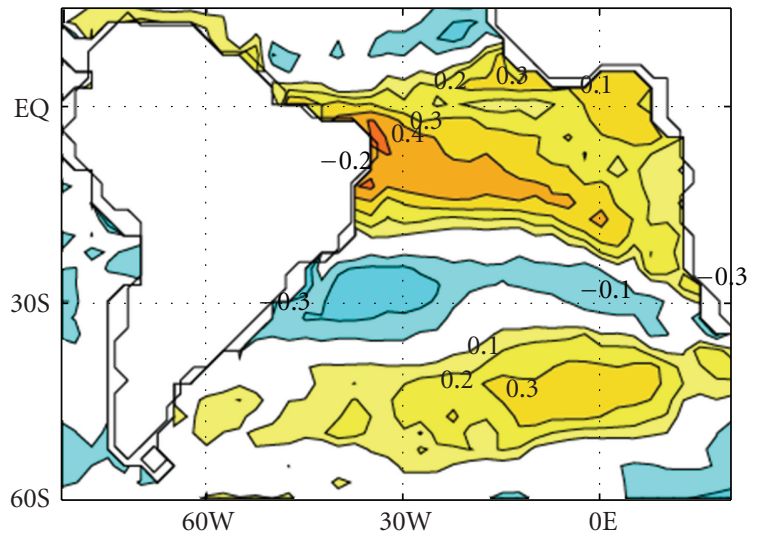

(d)

FIGURE 5: EOF1 in period P1 (a) and period P2 (b); contour interval: $0.25 \mathrm{~mm} /$ day. Correlation between the time series of EOF1 and SST anomalies in period P1 (c) and period P2 (d); contour interval: 0.1 . Correlation values higher (lower) than $0.2(-0.2)$ are significant at a $5 \%$ level according to a two-tailed Student $t$-test.
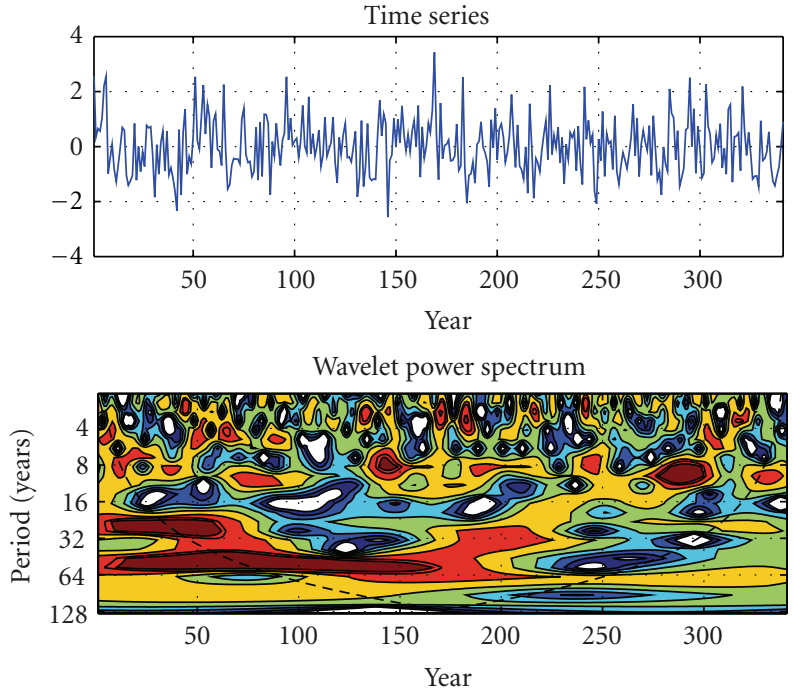

(a)
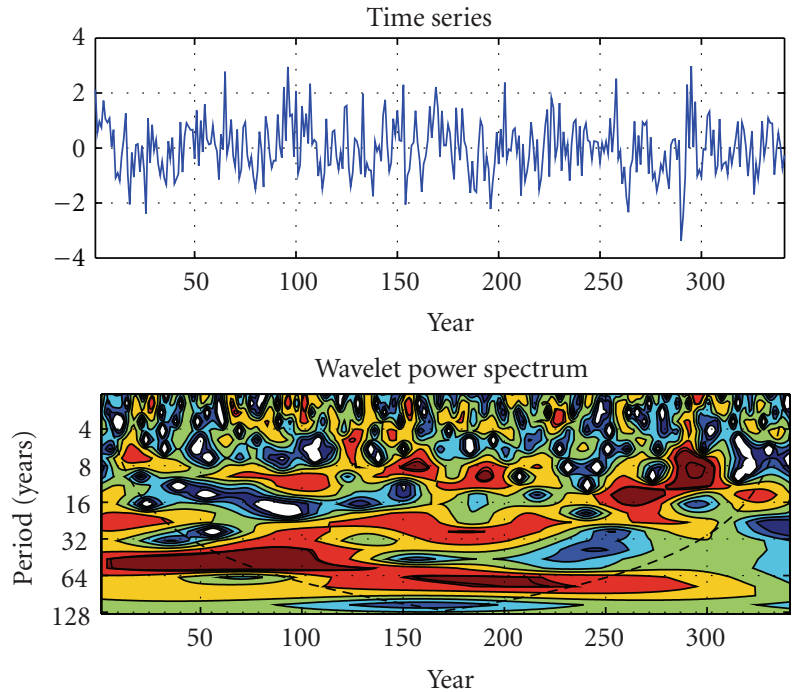

(b)

Figure 6: (a) Standardized time series of rainfall EOF1 for preindustrial run and wavelet (Morlet) analysis. (b) Standardized time series of index of south Atlantic SST defined as the average over the region $15^{\circ} \mathrm{S}-5^{\circ} \mathrm{S}, 330^{\circ} \mathrm{E}-345^{\circ} \mathrm{E}$, and wavelet (Morlet) analysis. In the wavelet analysis, color indicates power in each frequency band and regions that are significant to $5 \%$ level are indicated by black solid lines. Values outside the dashed line are affected by time boundaries. Wavelet software was provided by C. Torrence and G. Compo and is available at http://atoc.colorado.edu/research/wavelets/. 
oscillation in the record that is absent in the period P2. This 50-year oscillation, with weaker amplitudes, is also present in the time series of a south Atlantic index (average of SST within $\left.\left(15^{\circ} \mathrm{S}-5^{\circ} \mathrm{S}, 330^{\circ} \mathrm{E}-345^{\circ} \mathrm{E}\right)\right)$ only during $\mathrm{P} 1$ (Figure 6(b)). Also note that the largest values of the 4thorder coefficient of the polynomial of the potential coincide with the period when there is no dominating low-frequency oscillation in the record of the time series of EOF1 (see Figure 2).

\section{Detection of Anthropogenic Signal: A1B Scenario}

Regressing the future scenarios onto the EOF1 of precipitation in summer, we can determine the future evolution of this mode of variability. We use scenario A1B from 2000 to 2200. Figure 7 shows the evolution of EOF1 for the preindustrial run, 20th, 21st, and 22nd centuries. As can be seen, the mode of variability shows many time scales and no trend during the preindustrial and 20th-century runs. During the 21st century under the A1B forcing there is very little trend up to about year 2050. Interestingly, this is about the same time when the rate of $\mathrm{CO}_{2}$ emissions in $\mathrm{AlB}$ start to decrease from a maximum value. Afterwards, the mode shows a tendency for negative values of the pattern shown in Figure 1(b) which represents a wetting trend over SESA and a drying trend over the SACZ. The mode starts a tendency to recover 20thcentury conditions at the middle of the 22nd century.

We calculated the potential and associated pdf for the 200 years of the 21 st, and 22 nd centuries taking, as in the preindustrial case, window lengths of 100 years. Considering a mixture of two pdfs, we found that there is no evidence of deviations from a single peak distribution. Instead, as the climate evolves under the A1B scenario, the pdf just shifts toward negative mean values, keeping a unimodal distribution. An example is shown in Figure 8 comparing the pdf during the 20th century and the pdf of years 2080-2179.

Given the above results, determining when the evolution of the EOF1 is significantly affected by the greenhouse gases is analogous as determining when the pdf associated with the mode becomes different than the pdf that characterizes this mode of variability in the preindustrial run. As shown above, the evolution of the mode in the preindustrial run is characterized by different pdfs that are unimodal or bimodal depending on the interaction between rainfall and SST.

We first compare the pdf of the 20th century with those of the preindustrial run. The Kolmogorov test can not reject the hypothesis of pdfs belonging to the same population at the $10 \%$ level when comparing the 20th-century pdf with the pdfs of P1 and P2. This means that during the 20th century, the effect of greenhouse gases did not affect significantly the evolution of EOF1.

We next compare the pdf of the time series during the 21st and 22nd centuries taking a sliding window of 50 years with the pdfs of the preindustrial run during periods P1 and $\mathrm{P} 2$. For each time, we compute the $P$ value of the Kolmogorov test of similarity between the pdfs of the two populations and plot it in Figure 9. The results show that the time when
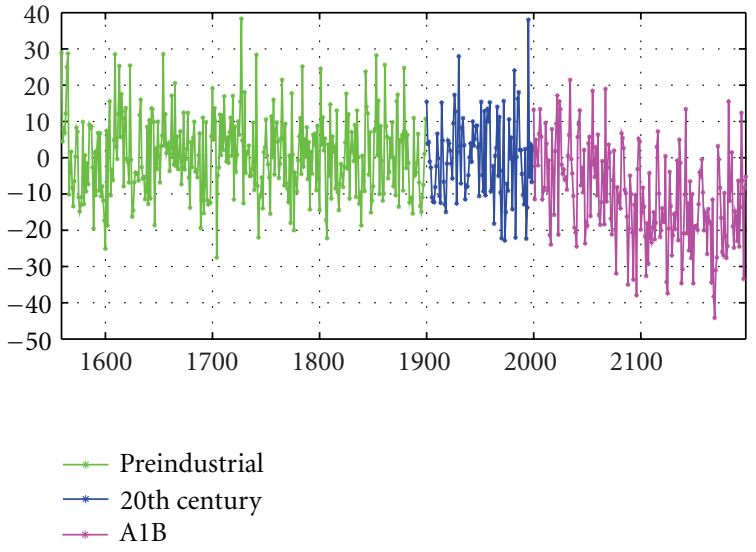

FIGURE 7: Time evolution of the rainfall EOF1 for the preindustrial run (green), the 20th century run (blue), and the A1B scenario (magenta). The time series are constructed projecting the precipitation anomalies, calculated with respect to the climatology of the 20th century, onto the spatial pattern of EOF1.

the influence of greenhouse gases on rainfall becomes significant depends on the pdf of the preindustrial period considered. If we compare the future pdfs with the pdf of P1 (unimodal) already after considering windows centered at 2029, the Kolmogorov test rejects the hypothesis (at the 10\% level) of the two pdfs coming from the same population (blue line). However, if we compare the future pdfs with the pdf of $\mathrm{P} 2$ (wide, bimodal), it is only after considering windows centered at 2048 that the greenhouse gases impact on rainfall becomes significant (at the 10\% level, red line). This clearly shows the importance of having good estimates of the natural variability of the climate system before attempting to attribute changes in rainfall behavior to greenhouse gas forcing.

\section{Summary and Discussion}

In this study we propose a methodology to characterize the summertime rainfall variability over South America and to determine when anthropogenic effects will become important. The methodology can be summarized as follows. First, calculate the simulated first EOF of 20th-century rainfall and compare it with observations to validate the model. Second, project the preindustrial run onto this mode to determine its time evolution and characterize the internal variability. Third, project $\mathrm{A} 1 \mathrm{~B}$ scenario onto the mode to determine the future time evolution. The last step is to compare the pdf of the projected scenario versus the pdf of the preindustrial run. In our study, the pdfs were constructed following the procedure of Livina et al. [22] and Kwasinok and Lohmann [23], and the Kolmogorov test was used to determine similarity between pdfs.

We found that rainfall variability over South America is characterized by a dipole with centers over the SACZ and SESA, as found by many authors before. Moreover, we found that the preindustrial run allows for pdfs that are statistically different and that represent different ocean-atmosphere coupling in the region. In one case, low-frequency ocean 


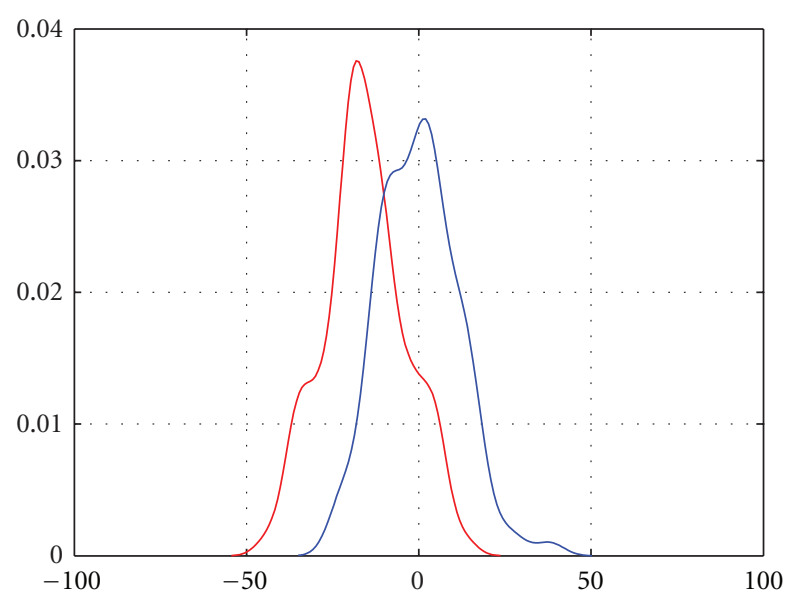

(a)

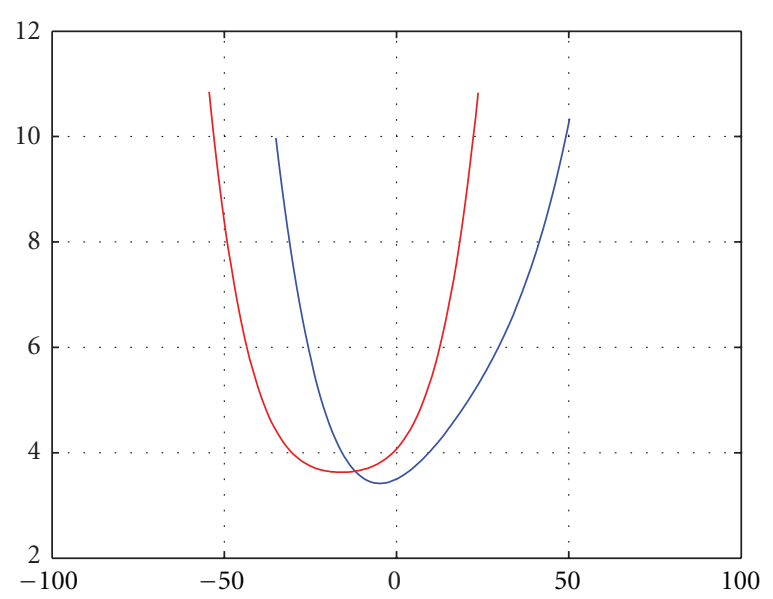

(b)

FIGURE 8: pdfs (a) and potential (b) of the time series of EOF1 for the 20th-century run (blue) and for A1B experiments during years 2080-2179 (red).

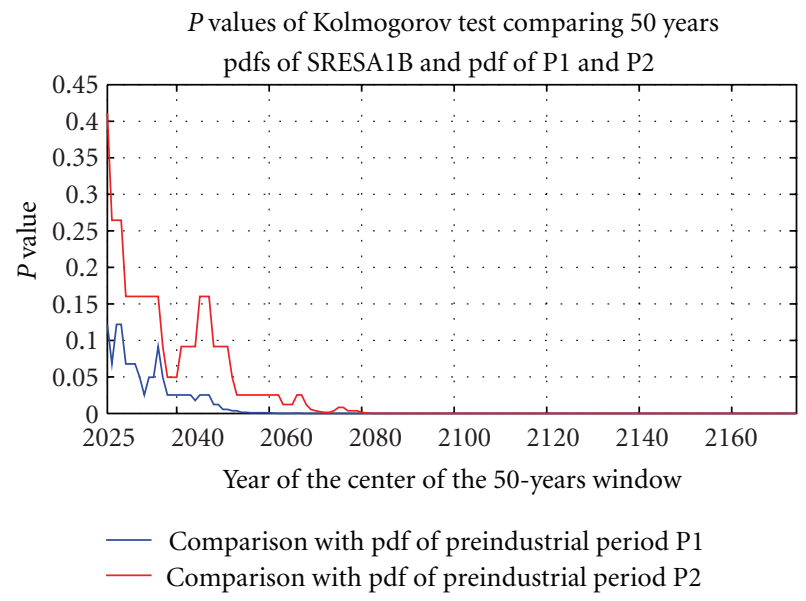

Figure 9: $P$ values of Kolmogorov test comparing the pdfs during 21 st and 22 nd centuries taking windows of 50 years with the pdfs of the preindustrial periods P1 (blue) and P2 (red). Values smaller than 0.1 means that the pdfs are statistically different at $10 \%$. The $P$-values are mapped at the middle of the sliding window.

variability forces rainfall over the SACZ inducing maximum anomalies over the ocean next to the south American coast, and the associated time evolution has a unimodal pdf. On the other hand, when ocean's influence is weak, the pdf is broad with no well-defined central peak. So, how does the ocean constrain the SACZ variability? We hypothesize the following mechanism.

Barreiro et al. [20, 21] showed that the total variability in the SACZ can be decomposed in a component due to internal atmospheric variability and an SST-forced component. In addition, they show that the internal variability is usually much stronger than the forced component and that they have different centers of action. Rainfall due to internal atmospheric variability has maximum anomalies over land and extends southwestward over the ocean, while the SST-forced component is restricted to the oceanic part of the SACZ.

Wainer and Venegas [25] have shown in previous model simulations that the South Atlantic Ocean presents a dipolelike multidecadal variability forced by changes in the intensity and location of the subtropical anticyclone. Moreover, they showed that the associated SST anomalies can force precipitation over the oceanic part of the SACZ. The period of the mode is about 25-30 years, which is half the one found here and is likely model dependent.

Internal atmospheric variability is likely always similar during the whole preindustrial run and thus the different rainfall behavior has to be related to the ocean. We found that during periods of large oceanic correlation, the maximum amplitude of rainfall anomalies is over the ocean, a region that is subject to the SST forcing. Thus, during this period (e.g., P1) warm tropical anomalies, associated with ocean multidecadal variability, enhance the SACZ close to the coast (and maybe shift it northwards), while negative anomalies to the south of $15^{\circ} \mathrm{S}$ decrease precipitation. These SST anomalies force the oceanic part of the SACZ, decreasing the variability there. Since the EOF1 has maximum weight over the SACZ, the associated time series will depend on its behavior and in this case it will result in a unimodal pdf. On the other hand, for example, in period P2 the absence of multidecadal variability causes the SST not to force a significant signal in the SACZ and thus the maximum rainfall anomalies are over land. This pattern in turn, in the absence of the driving from SST, can acquire larger amplitudes creating a wider pdf.

The existence of two possible internal variability regimes (and pdfs) in the model results in different time horizons when the anthropogenic signal will become evident. If the future is compared with the regime with a narrow pdf, the impact of greenhouse gases on rainfall is seen very early into 
the run (in 50-years windows centered at 2029 or later). If, instead, the future behavior of EOF1 is compared with the regime that has a wide pdf, then it is only after considering windows centered at 2048 that rainfall variability starts to change, stressing the importance of characterizing adequately the natural variability of the climate system in order to determine the impacts of anthropogenic forcing. Given the shortness of the observational record, this poses strong constraints when trying to detect changes in regional patterns of precipitation.

The dipole rainfall pattern used here as characterizing the summertime rainfall is ubiquitous in most climate models and observations and has been shown to occur on many different time scales from subseasonal to decadal. However, the results of this study are likely model dependent, in particular because rainfall is one of the most complicated variables to simulate and because coupled models represent oceanatmosphere interactions in different ways. Thus, to further support the findings of this study, it would be desirable to repeat the calculations with the output of the new generation of coupled models.

\section{Acknowledgment}

The research leading to these results has received funding from the European Community's Seventh Framework Programme (FP7/2007-2013) under Grant Agreement no. 212492 (CLARIS LPB, a Europe-South America network for climate change assessment and impact studies in La Plata Basin).

\section{References}

[1] E. Hawkins and R. Sutton, "The potential to narrow uncertainty in regional climate predictions," Bulletin of the American Meteorological Society, vol. 90, no. 8, pp. 1095-1107, 2009.

[2] A. Solomon, L. Goddard, A. Kumar et al., "Distinguishing the roles of natural and anthropogenically forced decadal climate variability: implications for prediction," Bulletin of the American Meteorological Society, vol. 92, no. 2, pp. 141-156, 2011.

[3] P. D. Jones and G. C. Hegerl, "Comparisons of two methods of removing anthropogenically related variability from the nearsurface observational temperature field," Journal of Geophysical Research D, vol. 103, no. 12, pp. 13777-13786, 1998.

[4] M. Collins, T. J. Osborn, S. F. B. Tett, K. R. Briffa, and F. H. Schweingruber, "A comparison of the variability of a climate model with paleotemperature estimates from a network of tree-ring densities," Journal of Climate, vol. 15, no. 13, pp. 1497-1515, 2002.

[5] T. P. Barnett, K. Hasselmann, M. Chelliah et al., "Detection and attribution of recent climate change: a status report," Bulletin of the American Meteorological Society, vol. 80, no. 12, pp. 2631-2659, 1999.

[6] IPCC 2007, G. C. Hegerl, F. W. Zwiers et al., "Understanding and Attributing Climate Change," in Climate Change 2007: The Physical Science Basis, S. Solomon, D. Qin, M. Manning et al., Eds., Contribution of Working Group I to the Fourth Assessment Report of the Intergovernmental Panel on Climate Change, Cambridge University Press, Cambridge, UK, 2007.
[7] P. A. Stott, S. F. B. Tett, G. S. Jones, M. R. Allen, W. J. Ingram, and J. F. B. Mitchell, "Attribution of twentieth century temperature change to natural and anthropogenic causes," Climate Dynamics, vol. 17, no. 1, pp. 1-21, 2001.

[8] S. F. B. Tett, R. Betts, T. J. Crowley et al., "The impact of natural and anthropogenic forcings on climate and hydrology since 1550," Climate Dynamics, vol. 28, no. 1, pp. 3-34, 2007.

[9] K. L. Swanson, G. Sugihara, and A. A. Tsonis, "Long-term natural variability and 20th century climate change," Proceedings of the National Academy of Sciences of the United States of America, vol. 106, no. 38, pp. 16120-16123, 2009.

[10] C. Junquas, C. Vera, L. Li, and H. Le Treut, "Summer precipitation variability over Southeastern South America in a global warming scenario," Climate Dynamics, vol. 38, no. 9-10, pp. 1867-1883, 2012.

[11] J. Nogués-Paegle and K. C. Mo, "Alternating wet and dry conditions over South America during summer," Monthly Weather Review, vol. 125, no. 2, pp. 279-291, 1997.

[12] M. E. Doyle and V. R. Barros, "Midsummer low-level circulation and precipitation in subtropical South America and related sea surface temperature anomalies in the South Atlantic," Journal of Climate, vol. 15, no. 23, pp. 3394-3410, 2002.

[13] V. Barros, M. Gonzalez, B. Liebmann, and I. Camilloni, "Influence of the South Atlantic convergence zone and South Atlantic Sea surface temperature on interannual summer rainfall variability in Southeastern South America," Theoretical and Applied Climatology, vol. 67, no. 3-4, pp. 123-133, 2000.

[14] A. W. Robertson and C. R. Mechoso, "Interannual and interdecadal variability of the South Atlantic convergence zone," Monthly Weather Review, vol. 128, no. 8, pp. 2947-2957, 2000.

[15] A. M. Grimm and M. T. Zilli, "Interannual variability and seasonal evolution of summer monsoon rainfall in South America," Journal of Climate, vol. 22, no. 9, pp. 2257-2275, 2009.

[16] J. N. Paegle and K. C. Mo, "Linkages between summer rainfall variability over South America and sea surface temperature anomalies," Journal of Climate, vol. 15, no. 12, pp. 1389-1407, 2002.

[17] P. Xie and P. A. Arkin, "Global Precipitation: A 17-year monthly analysis based on gauge observations, satellite estimates, and numerical model outputs," Bulletin of the American Meteorological Society, vol. 78, no. 11, pp. 2539-2558, 1997.

[18] C. Gordon, C. Cooper, C. A. Senior et al., "The simulation of SST, sea ice extents and ocean heat transports in a version of the Hadley Centre coupled model without flux adjustments," Climate Dynamics, vol. 16, no. 2-3, pp. 147-168, 2000.

[19] R. R. Chaves and P. Nobre, "Interactions between sea surface temperature over the South Atlantic Ocean and the South Atlantic Convergence Zone," Geophysical Research Letters, vol. 31, no. 3, Article ID L03204, 4 pages, 2004.

[20] M. Barreiro, P. Chang, and R. Saravanan, "Variability of the South Atlantic convergence zone simulated by an atmospheric general circulation model," Journal of Climate, vol. 15, no. 7, pp. 745-763, 2002.

[21] M. Barreiro, P. Chang, and R. Saravanan, "Simulated precipitation response to SST forcing and potential predictability in the region of the South Atlantic convergence zone," Climate Dynamics, vol. 24, no. 1, pp. 105-114, 2005.

[22] V. N. Livina, F. Kwasniok, and T. M. Lenton, "Potential analysis reveals changing number of climate states during the last 60 kyr," Climate of the Past, vol. 6, no. 1, pp. 77-82, 2010. 
[23] F. Kwasniok and G. Lohmann, "Deriving dynamical models from paleoclimatic records: application to glacial millennialscale climate variability," Physical Review E, vol. 80, no. 6, Article ID 066104, 2009.

[24] M. F. Schilling, A. E. Watkins, and W. Watkins, "Is human height bimodal?" American Statistician, vol. 56, no. 3, pp. 223229, 2002.

[25] I. Wainer and S. A. Venegas, "South Atlantic multidecadal variability in the climate system model," Journal of Climate, vol. 15, no. 12, pp. 1408-1420, 2002. 

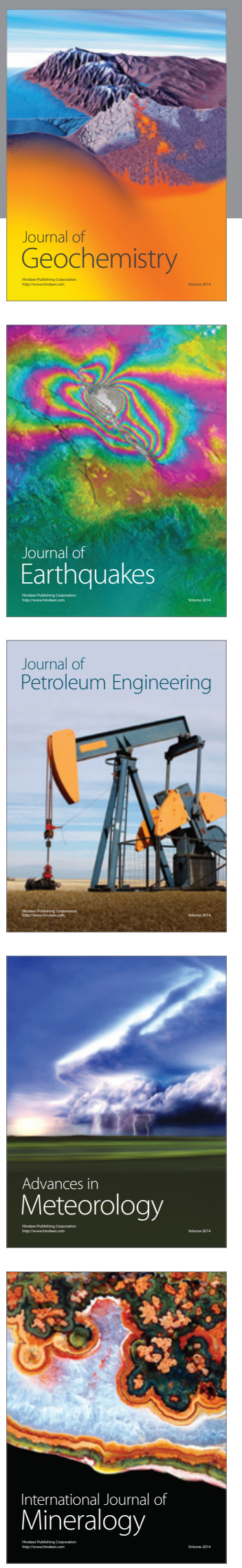
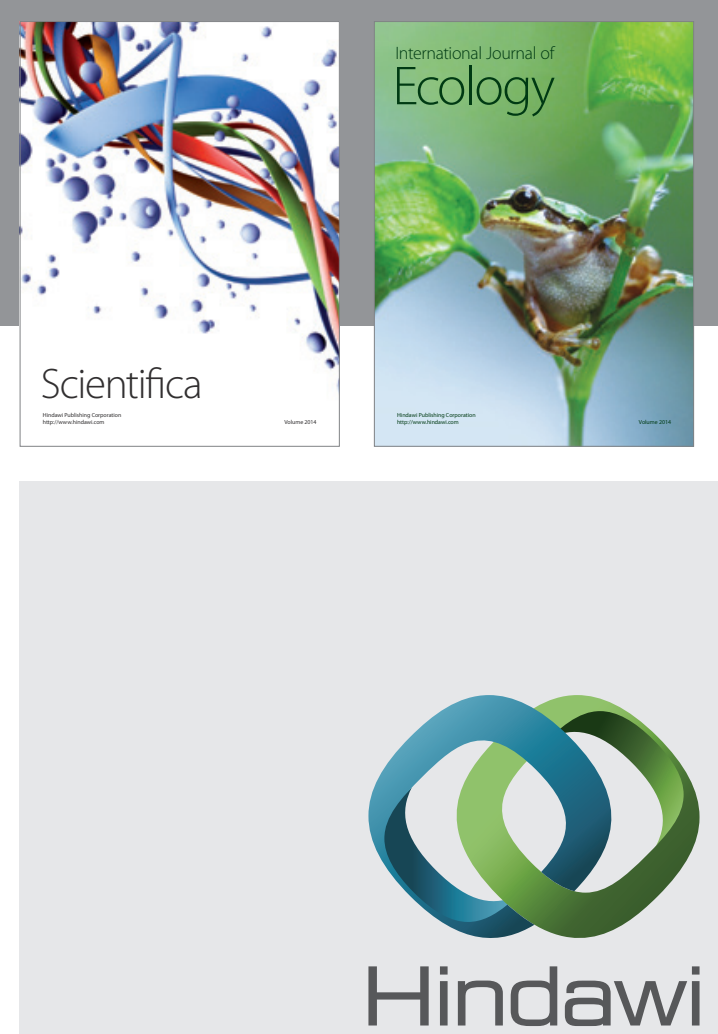

Submit your manuscripts at http://www.hindawi.com
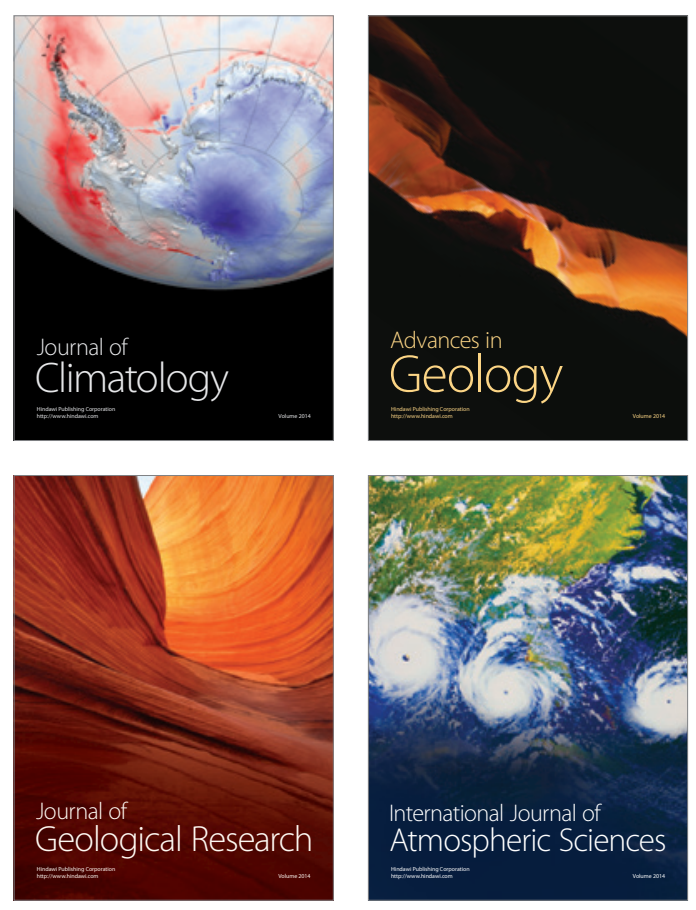
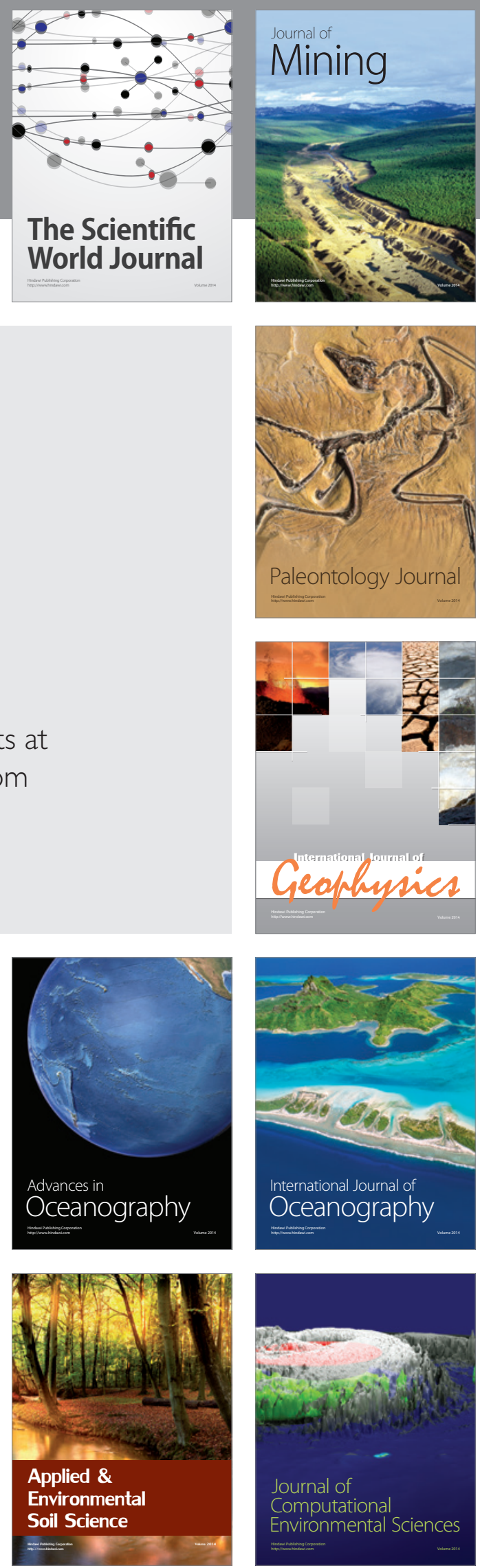